\title{
Detection of Aflatoxin M1 in Dairy Products Marketed in Iran
}

\author{
Behnam Barikbin ${ }^{1}$; Ali Allahresani ${ }^{2}$; Rasoul Khosravi ${ }^{1}$; Maryam Khodadadi ${ }^{1, *}$ \\ ${ }^{1}$ Social Determinants of Health Research Center, Environmental Health Engineering Department, Birjand University of Medical Sciences, Birjand, IR Iran \\ ${ }^{2}$ Chemistry Faculty, Birjand University, Birjand, IR Iran \\ ${ }^{*}$ Corresponding author: Maryam Khodadadi, Social Determinants of Health Research Center, Environmental Health Engineering Department, Birjand University of Medical Sciences, \\ Birjand, IR Iran. Tel: +98-5618825461; Fax:+98-5614440177, E-mail: maryam.khodadadi@gmail.com
}

Received: March 13, 2014; Revised: June 15, 2014; Accepted: October 3, 2014

\begin{abstract}
Background: There are different types of aflatoxins, including aflatoxin M1, M2, G1, G2, B1 and B2 produced in the food chain, especially when the food is infected with fungi and can directly be consumed by humans. Considering that our country is located in the subtropical geographic region where temperature and humidity ecological factors are among determining factors in contamination with AFM1 and aflatoxin, contamination of milk products, as carcinogens, is a serious risk to the community's health.

Objectives: The main goal of the present study was to measure M1 aflatoxin in distributed traditional and pasteurized cheese in South Khorasan.

Materials and Methods: In this cross-sectional and analytical study, 43 samples of traditional cheese and 59 samples of pasteurized cheese in three cities and 59 samples of pasteurized milk were randomly selected and their M1 aflatoxin was measured by means of the ELISA method. The obtained data was analyzed using the SPSS software (version 15).

Results: Amongst the collected samples, 34.3\% had measurable levels of aflatoxin; 32.6\% of traditional cheese and 35.6\% of pasteurized cheese and $94.9 \%$ of pasteurized milk had positive test results. Mean concentration of mycotoxin in the traditional cheese, pasteurized cheese and milk was $29.902 \pm 4.77,48.104 \pm 8.92$ and $22.394 \pm 4.77 \mathrm{ng} / \mathrm{L}$, respectively. Aflatoxin contamination levels in 12 samples of traditional cheese and 15 samples of pasteurized cheese were more than standard levels.

Conclusions: The high incidence of aflatoxin contamination in traditional and pasteurized cheese is worrying. Therefore, preventive measures that stop the entrance of the precursor of this poison (aflatoxin B1) into the food of lactating cattle are necessary.
\end{abstract}

Keywords:Aflatoxin M1; Milk; Cheese; Enzyme-Linked Immunosorbent Assay

\section{Background}

Aflatoxins are common toxic substances produced by the fungi Aspergillus flavus, Aspergillus parasiticus and Aspergillus nomius that contaminate corn and grain crops after harvest during the drying process $(1,2)$. Out breaks of aflatoxicosis (poisoning by aflatoxin) were first noted in the 1960s in England after more than 100000 turkeys on poultry farms died after consuming contaminated feed.Aflatoxins consist of four types including aflatoxin B1, B2, G1 and $\mathrm{G} 2$, which are biosynthesized by toxicogenic strains of Aspergillus flavus. Aflatoxin B1, M1 and G1 all cause cancer in animals. However, only aflatoxin B1 has been classified as a human carcinogen. The B1 toxin must be metabolized in order for it to be transformed into its carcinogenic form. Thus, aflatoxins M1 and M2 that are the hydroxylated metabolites of aflatoxin B1 and B2 may be found in milk and products obtained from livestock that have ingested contaminated feed (3).

The occurrence of aflatoxin M1 in milk is transitory in nature, usually reaching a peak within 12-24 hours (4) or four to five days (5), after the ingestion of aflatoxin-contaminated feed (4). Although the toxicity of AFM1 is less than that of its parent compound, AFM1 is known to be hepatotoxic and carcinogenic (6). Therefore its toxicity, initially clas- sified by the World Health Organization (WHO) International Agency for Research on Cancer (IARC) as a Group 2B human carcinogen (7), has now been classified as group 1 carcinogen $(8,9)$. European Commission (EC) regulations (10) established a maximum level of $0.05 \mu \mathrm{g} / \mathrm{kg}$ for aflatoxin M1 in liquid milk. However, the Institute of Standards and Industrial Research of Iran (11) has accepted $50 \mathrm{ng} / \mathrm{L}$ as the action level for AFM which is the same as the US food and drug administration (12) accepted level (13). Referring to scientific literature, many researchers from different countries have investigated the occurrence of AFM1 in milk and dairy products.

Numerous studies have been conducted on the incidence of AFM1 in dairy products in Iran $(3,5,13-17)$ and other worlds. For example some researchers $(1,2,4)$ have investigated aflatoxin M1 contamination of milk and cheese samples in Turkey and other parts of the world (5, $6,9)$. Turkish researcher's findings showed that $44.3 \%$ of samples had been contaminated with this toxic substance (30 to $3130 \mathrm{ng} / \mathrm{L}$ ). Similarly, a previous research measured the amount of aflatoxin M1 contamination in raw milk, pasteurized milk and ultra high temperature (UHT) milk from stores of Isfahan City by means of an ELISA kit and

Copyright (C2015, Health Promotion Research Center. This is an open-access article distributed under the terms of the Creative Commons Attribution-NonCommercial 4.0 International License (http://creativecommons.org/licenses/by-nc/4.0/) which permits copy and redistribute the material just in noncommercial usages, provided the original work is properly cited. 
showed that $55.9 \%$ of samples were contaminated at levels over the European standard limit. In 2008, aflatoxin M1 in raw milk from some regions of Iran was measured by means of the ELISA method, and the results showed that $12 \%$ to $100 \%$ of milk samples were infected with mycotoxin and contamination levels ranged from 50 to $352 \mathrm{ng} / \mathrm{L}$ (1315). Other researchers, evaluated pasteurized milk by using the ELISA kit in Mashhad City and demonstrated that 100\% milk samples were contaminated with aflatoxin M1 and contamination of $5.4 \%$ of these samples was more than the European limitation (14). In 2007 two investigators, separately published the results of their study on aflatoxin M1 contamination of milk and cheese in Tehran $(15,17)$. Sefidgar et al. (16) collected 120 raw milk samples from milk churns at 40 traditional and semi-industrial cattle farms located in Babol (Northern Iran) and analyzed them for AFM1 contamination by the ELISA method. Sixty-eight out of 120 samples (56.7\%) had AFM1 levels ranging from 50 to $352.3 \mathrm{ng} / \mathrm{L}$. Fifty-two samples (43.3\%) contained AFM1 at 4-50 ng/L. Furthermore, AFM1 contamination levels were 4-352.3 $\mathrm{ng} / \mathrm{L}$ with an average of $102.7 \mathrm{ng} / \mathrm{L}$. Their results indicated that $56.7 \%$ of samples were contaminated above the limit of the European commission regulations $(0.050 \mu \mathrm{g} / \mathrm{L})$. In other words, AFM1 contamination levels in raw milk were more than twice as high as permitted levels (16).

However, there is little information about the occurrence of AFM1 in milk and dairy products especially in Southern Khorasan Province (South east of Iran). This province has a tropical climate with conditions favorable for the growth of aflatoxigenic fungi.

Therefore, this study aimed to investigate the presence and levels of AFM1 in pasteurized milk and cheese samples marketed in Birjand and to compare the results with the legal regulations for AFM1 legislated by the European Commission, United States Food and Drug Administration (US FDA), and Institute of Standard and Industrial Research of Iran (ISIRI) $(11,12)$.

\section{Objectives}

The main goal of the present study was to measure M1 aflatoxin in distributed traditional and pasteurized cheese in South Khorasan.

\section{Materials and Methods}

\subsection{Samples}

A total of 161 non pasteurized and pasteurized milk and cheese samples, including 59 pasteurized milk samples produced by two local milk factories $\left(\mathrm{F}_{1}\right.$ and $\left.\mathrm{F}_{2}\right)$ of Southern Khorasan province, 43 non pasteurized traditional cheese samples from Birjand, Qhaen and Ferdows and 59 pasteurized cheese samples from three imported famous brands $\left(\mathrm{P}_{1}, \mathrm{P}_{2}\right.$ and $\left.\mathrm{P}_{3}\right)$, were purchased randomly from large supermarkets during Dec 2011 and Jan 2012, covering the winter season of Iran. All samples were stored at $4^{\circ} \mathrm{C}$ and analyzed for presence of AFM1 before their expiry date.

\subsection{Methods}

The quantity of AFM1 was determined using the Rocket International test kit (Cat. No EEM005096) and the competitive ELISA kit (ELISA Reader Anthos 2020, Italy), according to the procedures described by Rocket International. The AFM1 test kit included micro-titer plates coated with capture antibodies, AFM1 standard solutions (0 ppt, 5 ppt, 10 ppt, and 20 ppt), peroxidase-conjugated AFM1, substrate (urea peroxidase), chromogen (tetra methyl benzidine) and stop reagent containing 1 $\mathrm{N}$ sulfuric acid. Methanol, n-heptane and dichloromethane were purchased from Merck.

\subsection{Preparation of the Milk Samples for Analysis}

According the Rocket International test kit procedure, $10 \mathrm{~mL}$ of milk samples were chilled to $10^{\circ} \mathrm{C}$ and centrifuged for 10 minutes at $6000 \mathrm{rpm}$. After centrifugation, the upper fatty layer was removed, and $200 \mu \mathrm{L}$ of the defatted milk was used for the ELISA determination of AFM1.

\subsection{Preparation of Cheese Samples for Analysis}

One gram of traditional and pasteurized cheese was homogenized and then extracted with $5 \mathrm{~mL}$ of ethanol. The suspension samples were centrifuged for five minutes at $6000 \mathrm{rpm}$. In the next step, samples were evaporated followed by the addition of $1 \mathrm{~mL}$ of buffer and vortex at room temperature for five minutes. The samp was then mixed and centrifuged for five minutes at 6000 $\mathrm{rpm}$. The mixture was diluted $(1: 2 \mathrm{v} / \mathrm{v})$ by the addition of $0.3 \mathrm{~mL}$ of buffer and the upper phase of the sample solution. Other steps were the same as those for the preparation of milk samples. The data were analyzed by the t-test and ANOVA using the SPSS software version 15.

\subsection{Test Procedure}

Firstly, $200 \mu \mathrm{L}$ of distilled water was added to each well. Next, $200 \mu \mathrm{L}$ of the prepared sample solutions or AFM1 standards were added to the wells. The content of the plate was mixed gently by rocking the plate manually and the plate was incubated for 10 minutes at room temperature in the dark. The liquid was then removed completely from the wells and the wells were washed twice with distilled water. In the next step, $200 \mu \mathrm{L}$ of enzyme conjugate was added to each well and mixed by rocking the plate manually and incubated for $15 \mathrm{~min}$ utes at room temperature in the dark. Next, $200 \mu \mathrm{L}$ of chromogen stained in red was added to each well and mixed manually and incubated for 10 minutes at room temperature in the dark. Finally, $50 \mu \mathrm{L}$ of stop solution was added to each well, which led to color change from blue to yellow. The content of the wells were again gently mixed manually by rocking the plate and the absorbance of each well was measured at $450 \mathrm{~nm}$. 
Barikbin B et al.

\section{Results}

The standard curve for AFM1 detection is given in Figure 1. As can be seen from this figure, the calibration curve was found virtually linear in the 0-20 ppt range.

The occurrence of AFM1 in pasteurized milk that was present in a total of 59 samples from two milk factories $\left(\mathrm{F}_{1}\right.$ and $\left.\mathrm{F}_{2}\right)$ is shown in Table 1 . The mean value was 20.48 and $24.58 \mathrm{ng} / \mathrm{L}$ for $\mathrm{F}_{1}$ and $\mathrm{F}_{2}$, respectively. The results showed that $100 \%$ of pasteurized milk samples were contaminated with AFM1 yet in none of the samples, AFM1 was found at higher than the maximum acceptable limits $(50 \mathrm{ng} / \mathrm{L}$ ) of Iran and European Union regulations. The AFM1 concentrations of 59 pasteurized and 43 nonpasteurized traditional cheese samples from three of the biggest cities (Birjand, Qhaen and Ferdows) of Southern Khorasan and comparison with Iran's legal regulations are summarized in Table 2. Overall, 91 (56.5\%) of the 161 samples yielded aflatoxin M1: 56 (34.8\%) pasteurized milk samples, 14 (8.7\%) traditional cheese and 21 (13\%) pasteurized cheese samples. The study showed average aflatoxin concentrations of 29.9, 48.1, 57.32, 43.6, 43.84, 20.41 and $24.85 \mathrm{ng} / \mathrm{L}$ in traditional cheese, three imported famous brand including $\mathrm{P}_{1}, \mathrm{P}_{2}, \mathrm{P}_{3}$ pasteurized cheese, and $\mathrm{F}_{1}$ and $\mathrm{F}_{2}$ pasteurized milk samples, respectively.

Incidence of AFM1 contamination in dairy products consumed in Southern Khorasan was 56.5\% while only $16.8 \%$ of dairy products (only in pasteurized cheese (9.3\%) and traditional cheese (7.45\%) (Table 2 ) were contaminated at levels above the Iranian and EU legal limits. Therefore in 48.3\% (56 positive samples out of over all 161 samples) of pasteurized milk samples, AFM1 was not detected at levels above the legal limits.

Levels of AFM1 in pasteurized and traditional cheese and pasteurized milk are presented in Table 3. As indicated in by Table 3, aflatoxin M1 was found above measurable levels (5 ng/L) in 36.95\% (17.43) and 36.59\% (21/59) of traditional and pasteurized cheese samples, respectively. Therefore, most of the contaminated pasteurized and traditional cheese $(63.8 \%)$ contained AFM1 at levels of $<5$ ng/L.

As shown in Tables 4 and 1, the toxin was detected in 56 commercial pasteurized milk samples, corresponding to $94.9 \%$ of the total samples examined (56/59). Furthermore the toxin was above measurable levels $(5 \mathrm{ng} / \mathrm{L}$ ) in 93.5\% (29/31) and $96.4 \%(27 / 28)$ of $F_{1}$ and $F_{2}$ pasteurized milk samples, respectively. Most of the contaminated pasteurized milk samples (94.9\%) contained AFM1 at levels between 5 and $50 \mathrm{ng} / \mathrm{L}$. The results of the present study are comparable with those performed in other countries, which indicated the presence of AFM1 in milk or cheese samples (Table 5).

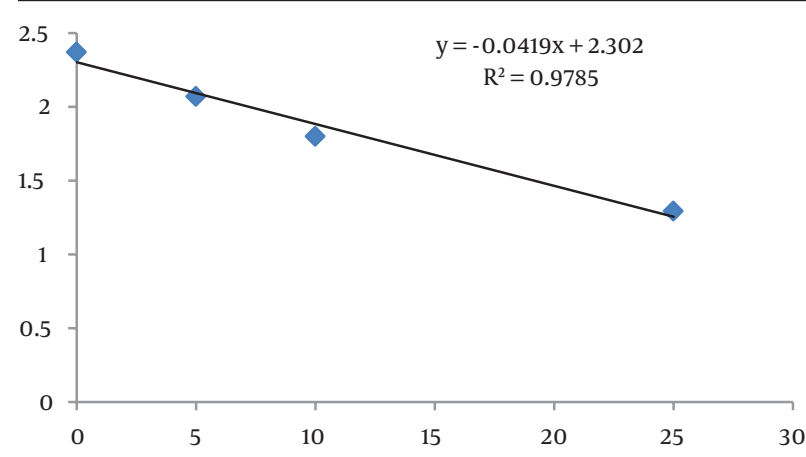

Figure 1. Standard Curve of AFM1 by Indirect Competitive Enzyme-Linked Immunosorbent Assay

Table 1. Occurrence of Aflatoxin M1 in Milk Samples From Different Companies Determined by the Enzyme-Linked Immunosorbent Assay

\begin{tabular}{lccccc}
\hline $\begin{array}{l}\text { Name of } \\
\text { Company }\end{array}$ & $\begin{array}{c}\text { Sample } \\
\text { Tested, } \mathbf{N}\end{array}$ & $\begin{array}{c}\text { Positive Sam- } \\
\text { ples, No. (\%) }\end{array}$ & Total Samples (mean \pm SEM) & Positive Samples, Min-Max & Exceed Legal Limit, No. (\%) \\
\hline F $_{\mathbf{1}}$ & 31 & $29(93.5)$ & $20.48 \pm 8.03$ & $0-35.24$ & 0 \\
F $_{\mathbf{2}}$ & 28 & $27(96.4)$ & $24.58 \pm 6.72$ & $0-34.28$ & 0 \\
Total & 59 & $56(94.9)$ & $22.394 \pm 7.66$ & $0-35.24$ & 0 \\
\hline
\end{tabular}

Table 2. Aflatoxin M1 Concentrations in Pasteurized and Traditional Cheese Samples Determined by ELISA

\begin{tabular}{|c|c|c|c|c|c|c|}
\hline \multirow[t]{2}{*}{ Samples } & \multirow{2}{*}{$\begin{array}{l}\text { Number of } \\
\text { Samples }\end{array}$} & \multirow{2}{*}{$\begin{array}{l}\text { Number of AFM1 } \\
\text { Positive Samples }\end{array}$} & \multicolumn{3}{|c|}{ AFM1 Concentration, ng/kg } & \multirow{2}{*}{$\begin{array}{l}\text { No. of Samples Above } \\
50(\mathbf{n g} / \mathrm{kg})(\%)\end{array}$} \\
\hline & & & Min & Max & Mean \pm SD & \\
\hline Birjand traditional cheese & 19 & $7(36.8)$ & 0 & 146.42 & $31.4 \pm 4.77$ & $6(31.6)$ \\
\hline Qhaen traditional cheese & 15 & $4(26.7)$ & 0 & 120.66 & $24.81 \pm 4.54$ & $3(20)$ \\
\hline Ferdows traditional cheese & 9 & $3(33.3)$ & 0 & 130.32 & $35.21 \pm 5.6$ & $3(33.3)$ \\
\hline$P_{1}$ pasteurized cheese & 19 & $8(42.1)$ & 0 & 313.85 & $57.32 \pm 9.34$ & $6(31.6)$ \\
\hline$P_{2}$ pasteurized cheese & 20 & $6(30)$ & 0 & 294.53 & $43.6 \pm 9.04$ & $4(20)$ \\
\hline$P_{3}$ pasteurized cheese & 20 & $7(35)$ & 0 & 339.61 & $43.84 \pm 8.8$ & $5(25)$ \\
\hline
\end{tabular}




\begin{tabular}{lccc}
\hline Table 3. Distribution of Aflatoxin M1 Content in Cheese Samples ${ }^{\text {a }}$ & & \\
\hline Aflatoxin range, $\mathbf{n g} / \mathbf{k g}$ & $\begin{array}{c}\text { Number of Traditional } \\
\text { Samples }(\mathbf{n}=\mathbf{4 3})\end{array}$ & $\begin{array}{c}\text { Number of Pasteurized } \\
\text { Samples }(\mathbf{n}=\mathbf{5 9})\end{array}$ & $\begin{array}{c}\text { Number of millk }\left(\mathbf{F}_{\mathbf{1}} \& \mathbf{F}_{2}\right) \\
\text { Samples }(\mathbf{n}=\mathbf{5 9})\end{array}$ \\
\hline$<\mathbf{5}$ & $29(67.44)$ & $38(64.4)$ & $3(5.08)$ \\
$\mathbf{5 - 5 0}$ & $2(4.65)$ & $6(10.1)$ & $56(94.91)$ \\
$\mathbf{5 1 - 1 5 0}$ & 12() 27.9 & $7(11.86)$ & $0(0)$ \\
$\mathbf{1 5 1 - 2 5 0}$ & $0(0)$ & $5(8.47)$ & $0(0)$ \\
$\mathbf{2 5 1 - 5 0 0}$ & $0(0)$ & $3(5.08)$ & $0(0)$
\end{tabular}

a Data are presented as No.(\%).

Table 4. Levels of Aflatoxin M1 in Traditional and Pasteurized Cheese Samples a

\begin{tabular}{|c|c|c|c|c|c|c|}
\hline \multirow[t]{2}{*}{ Cheese Product } & \multicolumn{6}{|c|}{ Distribution of Samples } \\
\hline & $<5 \mathrm{ng} / \mathrm{L}$ & $5-50 \mathrm{ng} / \mathrm{L}$ & $51-150 \mathrm{ng} / \mathrm{L}$ & $151-250 \mathrm{ng} / \mathrm{L}$ & 251-500 ng/L & $>500 \mathrm{ng} / \mathrm{L}$ \\
\hline Traditional (Birjand) & $12(63.2)$ & $1(5.3)$ & $6(31.6)$ & 0 & 0 & - \\
\hline Traditional(Qhaen) & $11(73.3)$ & $1(6.7)$ & $3(20)$ & 0 & 0 & - \\
\hline Traditional (Ferdows) & $6(66.7)$ & 0 & $3(33.3)$ & 0 & 0 & - \\
\hline $\mathbf{P}_{\mathbf{1}}$ & $11(57.9)$ & $2(10.5)$ & $3(15.8)$ & $2(10.5)$ & $1(5.3)$ & - \\
\hline $\mathbf{P}_{\mathbf{2}}$ & $14(70)$ & $2(10)$ & $1(5)$ & $2(10)$ & $1(5)$ & - \\
\hline $\mathbf{P}_{3}$ & $13(65)$ & $2(10)$ & $3(15)$ & $1(5)$ & $1(5)$ & - \\
\hline
\end{tabular}

Table 5. Prevalence of Pasteurized Milk Contamination Reported by Other Studies Found Above the Iranian and European Union Legal Limits ${ }^{a}$

\begin{tabular}{|c|c|c|c|}
\hline \multirow[t]{2}{*}{ Location } & \multirow[t]{2}{*}{ Pasteurized Milk Samples, No. } & \multicolumn{2}{|c|}{ Number of Contaminated Pasteurized Milk Samples } \\
\hline & & $>50 \mathrm{ng} / \mathrm{L}$ & $>500 \mathrm{ng} / \mathrm{L}$ \\
\hline \multicolumn{4}{|l|}{ Iran } \\
\hline Tabriz & 50 & $31(62)$ & 0 \\
\hline Babol & 72 & $72(100)$ & 0 \\
\hline Sanandaj & 272 & $12(4.4)$ & 0 \\
\hline Shiraz & 624 & $101(17.8)$ & 0 \\
\hline Tehran & 128 & $99(78)$ & 0 \\
\hline Kerman & 76 & $34(44.7)$ & 0 \\
\hline Urmia & 72 & $34(44.7)$ & 0 \\
\hline Shahrekord & 116 & $16(13.7)$ & $2(1.7)$ \\
\hline Mashhad & 110 & $110(100)$ & $6(5.4)$ \\
\hline Gonabad & 45 & $34(75.5)$ & 0 \\
\hline Birjand (present study) & 59 & 0 & 0 \\
\hline Japan & 208 & $207(99.5)$ & 0 \\
\hline Libya & 49 & $35(71.4)$ & 0 \\
\hline Turkey & 90 & $35(44.3)$ & 0 \\
\hline Brazil & 139 & $29(20.9)$ & 0 \\
\hline Germany & 379 & $2(0.5)$ & 0 \\
\hline Argentina & 77 & 0 & 0 \\
\hline Italy & 161 & 0 & 0 \\
\hline USA & 85 & $54(64)$ & 0 \\
\hline
\end{tabular}

\footnotetext{
a Data are presented as No.(\%).
} 


\section{Discussion}

Dairy products analysis indicated that $34.3 \%$ of samples had measurable levels of aflatoxin. Furthermore, 32.6\% of traditional cheese, $35.6 \%$ of pasteurized cheese and $94.9 \%$ of pasteurized milk samples had positive test results. Mean concentration of mycotoxin in the total traditional cheese, pasteurized cheese and milk was $29.902 \pm 4.77$, $48.104 \pm 8.92$ and $22.394 \pm 4.77 \mathrm{ng} / \mathrm{L}$, respectively.

Aflatoxin contamination levels in 12 samples of traditional cheese and 15 samples of pasteurized cheese were more than standard levels.

Some authors $(5,18)$ who have investigated the fate of AFM1 during cheese-making and cheese maturation agree that AFM1 content does not change significantly during these steps. These findings have also been confirmed by recent studies (Table 5) regarding the incidence of AFM1 contamination of cheese, which demonstrated the presence of AFM1 at various levels with a relevant incidence of positive samples (> $50 \mathrm{ng} / \mathrm{kg}$ ), and in some cases highly contaminated samples ( $>500 \mathrm{ng} / \mathrm{kg}$ ). Occurrence of AFM1 in dairy products other than cheese has also been assessed $(13,15,19)$, which demonstrates the potential risk for consumer health due to the widespread contamination of milk-derived products.

Two other studies in the region showed similar results i.e. AFM1 milk contamination being higher during winter months (like the present study) compared to other seasons. The first study was conducted in five regions of Iran. All samples were positive for AFM1 with an overall mean level of 53.1ng/L (19). Findings of this study showed higher AFM1 levels compared to the present study yet the second study from Sarab city, Iran, showed that $76.6 \%$ of 111 milk samples had positive test results, with AFM1 ranging from 15 to $28 \mathrm{ng} / \mathrm{L}$, which is similar to the present study.

Overall, traditional cheese, pasteurized cheese, and milk were contaminated with AFM1 at levels of 29.902 $\pm 4.77,48.104 \pm 8.92$ and $22.394 \pm 4.77 \mathrm{ng} / \mathrm{L}$, respectively. Therefore, all milk samples contained AFM1 below the maximum limit of $50 \mathrm{ng} / \mathrm{L}$ for milk in Iran. These results highlight the necessity of a survey involving a larger number of milk and milk product samples, and suggest that currently, the contamination of milk and milk products with AFM1 does not appear to pose a serious health problem in the Southern Khorasan province of Iran. studies conducted by Tekinsen et al. (2), Oruc, (5) and Barbiroli et al. (20) detected lower percentiles of AFM1 in samples contaminated with AFM1. However, the levels of AFM1 observed by Fallah et al. (13), Kamkar (15), Oveisi et al. (17) and Tajkarimi et al. (19), were significantly higher than those of the present study, ranging from $60 \%$ to $100 \%$. Concentrations of AFM1 in milk samples found by the present study are similar to reports from other countries $(2,5)$ although higher than reports from European countries (4, 20-22). When compared with reports from other Iranian cities they are lower than reports from Gorgan (76 ng/L), Rasht (44 ng/L), Shiraz (52 ng/L) and Tehran (61 ng/L) and higher than reports from Hamedan $(8 \mathrm{ng} / \mathrm{L})$, reported by Tajkarimi et al. (19). Also, our results showed that the levels of contaminations of pasteurized milk with AFM1 are in agreement with reports by Alborzi et al. (23) from Shiraz and rahimi et al. (18) from Isfahan and Shahrekord. Compared to other studies, which are shown in Table 5, AFM1 occurrence in Argentina and Italy was similar to our findings but AFM1 incidence in Babol (Iran) and Japan was greater and even higher than the maximum acceptable limit of European Union regulations. Besides, Table 5 shows that Birjand and Gonabad (Iran) that are near our study region had an anomalous contamination as compared to other studies. Differences in the reports of AFM1 from Birjand can be attributed to different brands of dairy products in Birjand as compared to Gonabad. The results of this study are in agreement with those obtained by previous reports (20-22) that indicated the presence of AFM1 in $18-45 \%$ of cheese samples. According to results obtained from traditional and pasteurized cheese samples, contamination levels of AFM1 in Iran seem to be a serious problem.

Although the amount of AFM1 in pasteurized milk in Southern Khorasan does not appear to create a serious public health problem at present, yet as compared to other studies, the results of the present study showed occurrence of AFM1 in milk and higher occurrence in cheese samples. Therefore, consumption of these products could be a serious public health problem especially in children. The best way to deal with this problem is to reduce AFB1 contamination in animal food-stuffs by improving process and storage practices. In addition, frequent analytical surveillance by food control agencies is highly recommended to control the incidence of mycotoxin contamination in Iran especially in imported dairy products and feed.

\section{Acknowledgements}

The authors would like to thank all those who assisted and participated in this study.

\section{Authors' Contributions}

The overall implementation of this study including design, data management and analysis, and manuscript preparation were the results of joint efforts by multiple individuals who are listed as co-authors of this paper. All authors have made extensive contributions in the review and finalization of this manuscript

\section{References}

1. Unusan N. Occurrence of aflatoxin M1 in UHT milk in Turkey. Food Chem Toxicol. 2006;44(11):1897-900.

2. Tekinsen KK, Eken HS. Aflatoxin M1 levels in UHT milk and kashar cheese consumed in Turkey. Food Chem Toxicol. 2008;46(10):3287-9.

3. Ghazani MH. Aflatoxin M1 contamination in pasteurized milk in Tabriz (northwest of Iran). Food Chem Toxicol. 2009;47(7):1624-5.

4. Kav K, Col R, Kaan Tekinsen K. Detection of aflatoxin M1 levels by ELISA in white-brined Urfa cheese consumed in Turkey. Food Control. 2011;22(12):1883-6.

5. Oruc HH, Cibik R, Yilmaz E, Kalkanli O. Distribution and stabil- 
ity of Aflatoxin M1 during processing and ripening of traditional white pickled cheese. Food Addit Contam. 2006;23(2):190-5.

6. Magliulo M, Mirasoli M, Simoni P, Lelli R, Portanti O, Roda A. Development and validation of an ultrasensitive chemiluminescent enzyme immunoassay for aflatoxin M1 in milk. J Agric Food Chem. 2005;53(9):3300-5.

7. International Agency for Research on Cancer.. Some naturally occurring substances: food items and constituents, heterocyclic aromatic amines and mycotoxins.Lyon, France; 1993.

8. Peraica M, Radic B, Lucic A, Pavlovic M. Toxic effects of mycotoxins in humans. Bull World Health Organ. 1999;77(9):754-66.

9. Pei SC, Zhang YY, Eremin SA, Lee WJ. Detection of aflatoxin M1 in milk products from China by ELISA using monoclonal antibodies. Food Control. 2009;20(12):1080-5.

10. European Commission(EC) Regulation.. Commission regulation (EC) No1881/2006 of 19 December 2006 setting maximum levels for certain contaminants in foodstuffs. Off J Eur Communities. 2006:364-525.

11. ISIRI.. Milk and milk products-raw milk-specifications and test methods. 2nd edKaraj, Iran: Iranian National Standard; 2005.

12. US Food and Drug Administration.. Sec. 527.400 in FDA compliance policy guides.Washington, DC: FDA; 1996.

13. Fallah AA. Assessment of aflatoxin M1 contamination in pasteurized and UHT milk marketed in central part of Iran. Food Chem Toxicol. 2010;48(3):988-91.

14. Hassanzadeh Khayat M, Mortazavi A, Kohestani GH, Bakhtiarizadeh K, Akhavan H. Determination of aflatoxin M1 concentration in pasteurized milk in Mashhad, northeast of Iran. Iran J Basic Med Sci.1999;2:24-9.
15. Kamkar A. A study on the occurrence of aflatoxin M1 in Iranian Feta cheese. Food Control. 2006;17(10):768-75.

16. Sefidgar SA, Azizi G, Khosravi AR, Roudbar-Mohammadi S. Presence of Aflatoxin M1 in raw milk at cattle farms in Babol, Iran.Pak JBiol Sci. 2008;11(3):484-6.

17. Oveisi MR, Jannat B, Sadeghi N, Hajimahmoodi M, Nikzad A. Presence of aflatoxin M1 in milk and infant milk products in Tehran, Iran. Food Control. 2007;18(10):1216-8.

18. Rahimi E, Shakerian A, Jafariyan M, Ebrahimi M, Riahi M. Occurrence of aflatoxin M1 in raw, pasteurized and UHT milk commercialized in Esfahan and Shahr-e Kord, Iran. Food Sec. 2009;1(3):317-20.

19. Tajkarimi M, Shojaee Aliabadi F, Salah Nejad M, Pursoltani $H$, Motallebi AA, Mahdavi H. Seasonal study of aflatoxin M1 contamination in milk in five regions in Iran. Int J Food Microbiol. 2007;116(3):346-9.

20. Barbiroli A, Bonomi F, Benedetti S, Mannino S, Monti L, Cattaneo $\mathrm{T}$, et al. Binding of aflatoxin M1 to different protein fractions in ovine and caprine milk. J Dairy Sci. 2007;90(2):532-40.

21. Battacone G, Nudda A, Palomba M, Pascale M, Nicolussi P, Pulina G. Transfer of aflatoxin B1 from feed to milk and from milk to curd and whey in dairy sheep fed artificially contaminated concentrates. J Dairy Sci. 2005;88(9):3063-9.

22. Galvano F, Galofaro V, de Angelis A, Galvano M, Bognanno M, Galvano G. Survey of the occurrence of aflatoxin M1 in dairy products marketed in Italy. J Food Prot. 1998;61(6):738-41.

23. Alborzi S, pourabbas B, Rashidi M, Astaneh B. Aflatoxin M1 contamination in pasteurized milk in Shiraz (south of Iran). Food Control. 2006;17(7):582-4. 